\title{
A Brief Journey of Tocotrienols as Anticancer Agents
}

\author{
Kabir ${ }^{1{ }^{*}}{ }^{,}$, Rahman $\mathbf{M}^{1}$, Rahman $\mathrm{K}^{2}$ and Islam $\mathrm{T}^{3}$ \\ ${ }^{1}$ Department of Pharmacy, International Islamic University Chittagong, Bangladesh \\ ${ }^{2}$ Department of Pharmacy, University of Sydney, Australia \\ ${ }^{3}$ Department of Medicine, Royal Melbourne Hospital, University of Melbourne, Australia
}

${ }^{*}$ Corresponding author: Imtiazul Kabir, Department of Pharmacy, International Islamic University Chittagong University of Chittagong, Kumira, Chittagong, Bangladesh, Tel: +88-01714489798; E-mail: md.i.kabir1990@gmail.com

Received date: June 15, 2017; Accepted date: July 03, 2017; Published date: July 10, 2017

Citation: Kabir I, Rahman M, Rahman K, Islam T (2017) A Brief Journey of Tocotrienols as Anticancer Agents. J In Silico In Vitro Pharmacol. Vol. 3 No. $2: 19$.

Copyright: (C) 2017 Kabir I, et al. This is an open-access article distributed under the terms of the Creative Commons Attribution License, which permits unrestricted use, distribution, and reproduction in any medium, provided the original author and source are credited.

\section{Abstract}

The journey of tocotrienol is started when the Vitamin $E$ was first discovered as the fertility factor. Later in the research studies vitamin $\mathrm{E}$ was found to be consisting of eight isomers which can be divided into two separate groups known as tocopherols and tocotrienols. The isomers share similarity in structure but differ at much levels based upon their functional or biological properties. Initially tocopherols were investigated much due to their powerful antioxidant properties. However, the other four isomers of tocotrienols were found to be consisting of anticancer properties at varying degree in vitro and in vivo. The mechanisms mediated by tocotrienols such as NFkB pathway, apoptosis, and effect on DNA polymerases are totally different to those of tocopherols.

Keywords: Tocotrienols; Vitamin E; Anticancer activity; Tocopherols

\section{Introduction}

Natural compounds have been studied in various fields since many decades for their pharmacological activities [1-3]. When the Vitamin E was first identified, the $\alpha$-tocopherol was found to be possessing potent antioxidant property [4]. Later four isomers of tocopherols known as $\alpha, \beta, \gamma$, and $\delta$ tocopherols were identified which differ from each other based upon the methyl group substitution on the chromanol ring which also have varying potency of antioxidant property. Other four isomers of vitamin $\mathrm{E}$ were identified later which differ from their respective tocopherols based upon the unsaturation of the isoprenoid side chain (Figures 1-2) [5]. Tocotrienols became main interest research after they were proven to be effective anticancer agents [6]. Palm oil, rice bran oil, grape fruit seed oil, oats, hazelnuts, maize, olive oil, Buckthorn berry, rye, flax seed oil, poppy seed oil and sunflower oil are natural sources of tocotrienols at varying yields [7].
Tocotrienols have the unsaturated side chain which is useful for their penetration into the various organs and fatty tissues [8]. Structurally tocotrienols contain three major parts. The phenolic hydroxyl group is essential for their antioxidant activity. Phytyl side chain is essential for their membrane binding and further absorption. However, the oral absorption of tocotrienols is very negligible when compared to the tocopherols due to their lower association with $\alpha$-tocopherol transfer protein ( $\alpha$-TTP) [9]. However, tocotrienols need to be absorbed in the similar fashion to tocopherols. Presence of food increases their absorption. Tocotrienols form micelles in the gut and form chylomicrons which can be further entered into the lymphatic system.

The rate limiting step for bioavailability of any compound is their absorption and metabolism [10]. Tocopherols and tocotrienols are degraded by same mechanism because of their structural similarity. First, cytochrome p450 enzymes carry the $\omega$ hydroxylation on the tocols [11]. Most probable CYP enzymes in this are cyp3A4 and cyp4F2. Next, $\beta$ oxidation takes place. The final products of all forms are the respective carboxyethylhydroxychromans (CEHC). These chromans are more aqueous soluble and excreted in urine [11].

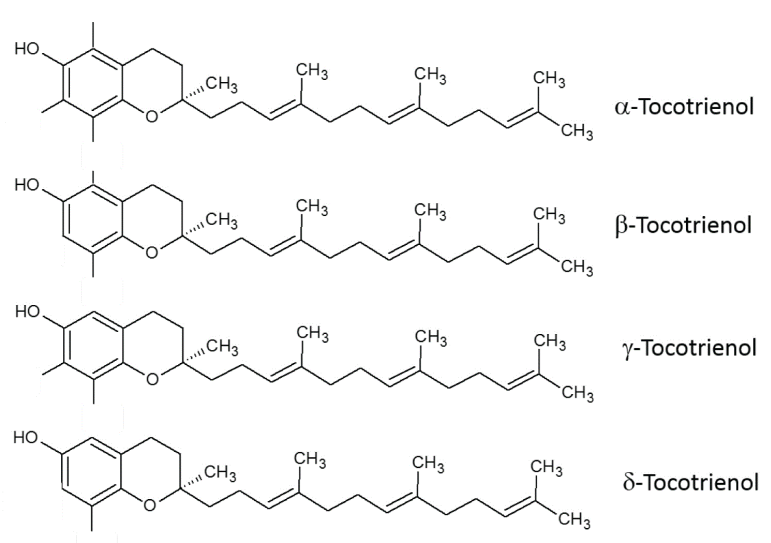

Figure 1: Structure of tocotrienols. 


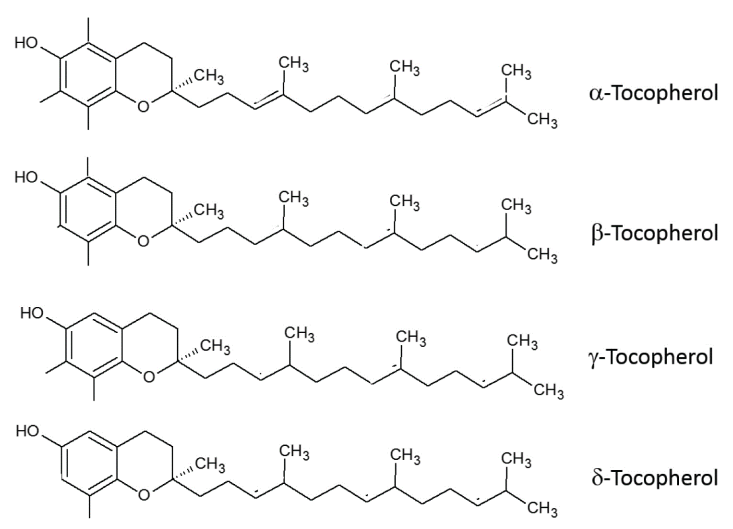

Figure 2: Structure of tocopherols.

Successful in vitro and in vivo studies are available to prove the anticancer activities of tocotrienols in wide range of cancers and other health disorders [6,12-16]. Studies are also being conducted to advantage of alternative formulation (Figure 3) types to enhance bioavailability of the drugs [17-19].

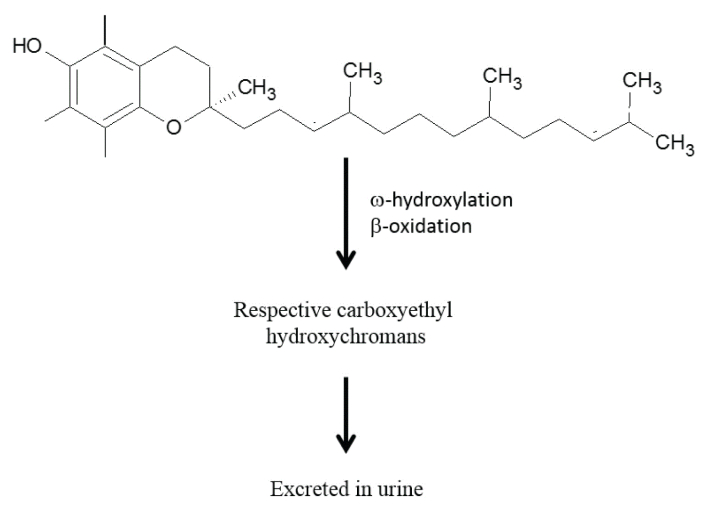

Figure 3: Metabolism of tocopherols.

Studies were conducted to compare the oral bioavailability of tocopherols and tocotrienols when administered in vivo in form of oil solutions $[20,21]$. These studies also made insights into the intestinal solubilization and permeability of the same. $\gamma$ Tocotrienol and $\alpha$ tocopherol were mixed with intestinal phospholipids to form the micelles. This mimics the in vivo intestinal condition for the drugs in the intestinal perfusion model. To observe the role of carrier mediated uptake through Niemann-PickC1-like1 (NPC1L1) transporter, Ezetimibe was used which is the inhibitor of NPC1L1. In vitro dissolution studies and HPLC analysis indicated that the dissolution rate and fraction of dissolution is higher for $\gamma$ tocotrienol compared to that of $\alpha$ tocopherol. At the same time, both of them had lower dissolution in total. When the NPC1L1 was inhibited in the intestinal perfusion studies, it was observed that the passive permeability of $\alpha$ tocopherol is 19 fold higher compared to that of $\gamma$ tocotrienol. However, when there is no inhibition on the transporter, the $\alpha$ tocopherol was completely permeable with Peff $45.6 \times 10^{-5} \mathrm{~cm} / \mathrm{s}$, compared with 26.3 $\times 10^{-5}+9.2 \times 10^{-5} \mathrm{~cm} / \mathrm{s}$ for $\gamma$ T3 $[20,21]$.

\section{Anticancer Activities of Tocotrienols}

Cancer is the biggest threat to mankind due to its aggressive, uncontrollable growth and metastatic properties [22-26]. The first ever anticancer activity of tocotrienols was found by Komiyama et al. The research group developed tumor model in mice by injecting cells i.p. and further treated them with tocopherol or tocotrienols i.p. injections. The results indicated that $\gamma$ tocotrienol increased life expectancy in mice with fibrosarcoma compared to the $\alpha$ tocotrienol and tocopherols but does not have any significant anticancer activity against P388 leukemia [27]. The study also further had insights on tocotrienol mediated anticancer activity towards human and mouse cell lines in vitro. Further the agents do not have significant toxicity on the animals [27].

Later many other research groups extended their study on the anticancer properties of the tocotrienols against various cancer types. When chemically induced tumor bearing rats were given a diet of corn oil, palm oil and soya bean oil, it was observed that palm oil fed rats have lower incidence of tumor appearance and also lower number of tumors compared to the other two groups [28]. In different set of studies, it was observed that the palm oil is the major source of Tocotrienols which are proven to be the potent in vitro anticancer agents [29-31]. Palm oil represents one of the most abundant natural sources of tocotrienols [31].

In similar experiments in rats, tocotrienol activity was measured in hepato-carcinogenesis. Rats were fed with 2acetylaminofluorene (AAF) and treated with tocotrienols for few weeks [32]. Results indicated that the tocotrienol treated rats have lower tendency to show liver cell damage compared to the AAF alone treated mice. The effects of tocotrienol were measured by the decreased activities of both plasma and liver microsomal gamma-glutamyl transpeptidase (GGT) and liver microsomal UDP-glucuronyl transferase (UDP-GT). This strongly suggests the tocotrienol reducing effect on severity of hepato carcinogenesis [32].

Among all the cancers, breast cancer is the mostly studied to evaluate the anticancer activity of tocotrienols [13,33-35]. In one of the studies, tocotrienols displayed potent in vitro anticancer activity against highly malignant +SA mammary cancer cells with minimum toxicity on the normal mammary epithelial cells. At the same time, even higher doses of tocopherols did not have any significant anticancer activity on the same malignant cells [36]. The anticancer activity was measured in the terms of decreased proliferation. Further it was shown that tocotrienol mediated decreased mammary cancer cell proliferation was mediated by decreased Akt activity and NFkB transcriptional down regulation [37].

Even significant research was done to show the apoptotic ad other pathway mediated anti proliferative activity of tocotrienols, it is not clear at the gene level. In one study oestrogen dependent and independent mouse mammary cancer cells were treated with tocotrienols and further DNA micro array was performed [38]. The results indicated three affected gene regulators including c-myc binding protein $\mathrm{MM}-1,23-\mathrm{kDa}$ highly basic protein, and interferon-inducible 
protein 9-27 (IFITM-1). These are essential in cell cycle progression, and differentiation of tumor cells [38].

Annatto seeds being the major source of tocotrienols, Annatto T3 was investigated for its in vitro and in vivo anticancer activity in HER-2/new transgenic mice [39]. The experimental mice were studies for apoptosis, senescent like growth arrest, immune modulation and oxidative effect. Results indicated strong anticancer activity of annatto tocotrienol in terms of reduced number of tumors, decreased tumor size and lung metastatic tumors. However, no significant immune modulation was observed. This is the first ever spontaneous breast cancer model in mice with annatto tocotrienol supplementation [39].

Other studies showed that dietary supplementation with TRF inhibited growth of +SA mammary tumors transplanted in female syngeneic BALB/c mice [40]. However, these antitumor effects of dietary TRF supplementation did not produce a typical dose-responsive effect. These findings indicate that the anticancer effectiveness of oral administration of tocotrienols may be limited due to inefficient or saturated uptake/transport mechanisms within the gut and circulation. Nevertheless, experimental evidence strongly suggested that tocotrienols provide potential health benefits in the treatment of cancer [40].

\section{Targeted Delivery of Tocotrienols}

Maintaining desired concentrations of tocotrienols at target is difficult to achieve because of their low bioavailability and increase excretion rate. Few studies were conducted to improve their in vivo activity by making semi synthetic derivatives which had shown promising results in mice model of breast cancer [41-43]. In a recent published article, tocotrienol was targeted by using targeted vesicles [44]. These vesicles were conjugated by transferrin and loaded with either tocopherols or tocotrienols. Further, vesicles were characterized by electron microscopy observations, transferrin assays, size distribution and zeta potential measurements. In vitro assessment was done by treating cancer cells in vitro to measure viability and cellular uptake of drug. In vivo experiments were carried out by i.v. administration of the vesicles into tumor bearing mice. Upon testing the in vivo efficacy, it was observed that $\alpha$ tocotrienol alone has significant efficacy against cancer cells in vivo. The tumor regression was observed starting day 1 until 11 days. Later, few tumors still maintained regression under influence of $\alpha$ tocotrienol treatment. However, all other tocotrienols were targeted to the site with transferrin conjugated vesicles. Moreover, there is no sign of any toxicity in the animals underwent treatment [44].

\section{Conclusion}

Other than the biological properties mentioned in this review, tocotrienols exert many other activities including bone resorption, diabetes, cardiovascular and neurological diseases in vitro and in vivo. A lot much research is needed further to make them use in drug market. Tocotrienols also prevents or provides protection against Alzheimer's disease, Parkinson's disease, and Huntington's disease. To avoid the problems with poor availability novel pro drug derivatives, semisynthetic derivatives, and delivery systems such as nano particles, nano emulsions, and sustained release formulations can be developed. Also we can take advantage of synergistic properties of tocotrienols with other available chemotherapeutic agents.

\section{Conflict of Interest}

Authors do not have any conflict of interest to declare.

\section{References}

1. Shahidi F (1997) Natural antioxidants: chemistry, health effects, and applications. 1997: The American Oil Chemists Society.

2. Gullett NP, Ruhul Amin AR, Bayraktar S, Pezzuto JM, Shin DM, et al. (2010) Cancer prevention with natural compounds. Semin Oncol 37: 258-281.

3. Hosain SB, Sultana S, Haque A (2011) Studies on antibacterial, cytotoxic and antioxidant properties of the seeds and leaves of Ficus racemosa. IJPSR 2: 1040-1045.

4. Evans HM, Bishop KS (1922) On the existence of a hitherto unrecognized dietary factor essential for reproduction. Science 56: 650-651.

5. Whittle K, Dunphy P, Pennock J (1966) The isolation and properties of $\delta$-tocotrienol from Hevea latex. Biochem J 100: 138-145.

6. Guthrie N, Gapor A, Chambers AF, Carroll KK (1997) Inhibition of proliferation of estrogen receptor-negative MDA-MB-435 andpositive MCF-7 human breast cancer cells by palm oil tocotrienols and tamoxifen, alone and in combination. J Nutr 127: 544S-548S.

7. Ahsan H, Ahad A, Iqbal J, Siddiqui WA (2014) Pharmacological potential of tocotrienols: a review. Nutr Metabol 11: 52.

8. Suzuki YJ, Tsuchiya M, Wassall SR, Choo YM, Govil G, et al. (1993) Structural and dynamic membrane properties of alphatocopherol and alpha-tocotrienol: implication to the molecular mechanism of their antioxidant potency. Biochemistry 32: 10692-10699.

9. Rigotti A (2007) Absorption, transport, and tissue delivery of vitamin E. Mol Aspects Med 28: 423-436.

10. Lodge JK (2005) Vitamin E bioavailability in humans. J Plant Physiol 167: 790-796.

11. Brigelius-Flohe R (2006) Bioactivity of vitamin E. Nutr Res Rev 19: $174-186$.

12. Chan KK, Oza AM, Siu LL (2003) Statins as Anticancer Agents. Clin Cancer Res 9: 10-19.

13. Nesaretnam K, Stephen R, Dils R, Darbre P (1998) Tocotrienols inhibit the growth of human breast cancer cells irrespective of estrogen receptor status. Lipids 33: 461-469.

14. Srivastava JK, Gupta S (2006) Tocotrienol-rich fraction of palm oil induces cell cycle arrest and apoptosis selectively in human prostate cancer cells. Biochem Biophys Res Commun 346: 447-453. 
15. Kannappan R, Gupta SC, Kim JH, Aggarwal BB (2012) Tocotrienols fight cancer by targeting multiple cell signaling pathways. Genes Nutr 7: 43-52.

16. Ananthula S (2014) Bioavailability and bioequivalence issues associated with oral anticancer drugs and effect on drug market. J Bioequiv Availab 6: e56.

17. Brannon-Peppas L, Blanchette JO (2012) Nanoparticle and targeted systems for cancer therapy. Adv Drug Deliv Rev 64: 206-212.

18. Imai H, Misra GP, Wu L, Janagam DR, Gardner TW, et al. (2015) Subconjunctivally implanted hydrogels for sustained insulin release to reduce retinal cell apoptosis in diabetic rats hydrogels for sustained retinal delivery of insulin. IOVS 56: 7839-7846.

19. Janagam DR, Wang L, Ananthula S, Johnson JR, Lowe TL (2016) An accelerated release study to evaluate long-acting contraceptive levonorgestrel-containing in situ forming depot systems. Pharmaceutics 8: e28.

20. Abuasal B, Sylvester PW, Kaddoumi A (2010) Intestinal absorption of $\gamma$-tocotrienol is mediated by Niemann-Pick C1-Like 1: in situ rat intestinal perfusion studies. Drug Metab Dispos 38: 939-945.

21. Abuasal BS, Qosa H, Sylvesteret PW (2012) Comparison of the intestinal absorption and bioavailability of ptocotrienol and atocopherol: in vitro, in situ and in vivo studies. Biopharmaceut Drug Dispos 33: 246-256.

22. Ananthula S, Sinha A, El Gassim M, Batth S, Marshall GD, et al. (2016) Geminin overexpression-dependent recruitment and crosstalk with mesenchymal stem cells enhance aggressiveness in triple negative breast cancers. Oncotarget 7: 20869-20889.

23. Stewart BW, Christopher (2014) World cancer report.

24. Kamangar, F, Dores GM, Anderson WF (2006) Patterns of cancer incidence, mortality, and prevalence across five continents: defining priorities to reduce cancer disparities in different geographic regions of the world. J Clin Oncol 24: 2137-2150.

25. Stewart BW, Kleihues P (2003) World cancer report. IARC Press: Lyon.

26. Raghu K, Neilson EG (2003) Epithelial-mesenchymal transition and its implications for fibrosis. J Clin Invest 112: 1776-1784.

27. Komiyama $K$, lizuka $K$, Yamaoka $M$, Watanabe $H$, tsuchiya $N$, et al. (1989) Studies on the biological activity of tocotrienols. Chem Pharm Bull 37: 1369-1371.

28. Sundram K, Khor HT, Ong AS, Pathmanathan R (1989) Effect of dietary palm oils on mammary carcinogenesis in female rats induced by 7, 12-dimethylbenz (a) anthracene. Cancer Res 49: 1447-1451.

29. Ananthula S (2014) Mechanisms mediating tocotrienol derivative in vitro and in vivo anticancer effects and inhibition of compensatory responses to hypoxia in the highly malignant mouse+ SA mammary cancer cells.
30. Ananthula S, Parajuli P, Behery FA, Alayoubi AY, Nazzal S, et al. (204) $\delta$ Tocotrienol Oxazine Derivative Antagonizes Mammary Tumor Cell Compensatory Response to CoCl2-Induced Hypoxia. BioMed Res Int 2014: 13.

31. Elson CE, AlfinSlater RB (1992) Tropical oils: nutritional and scientific issues. Crit Rev Food Sci Nutr 31: 79-102.

32. Ngah W, Jarien Z, San MM, Marzuki A, Top GM, et al. (1991) Effect of tocotrienols on hepatocarcinogenesis induced by 2acetylaminofluorene in rats. Am J Clin Nutr 53: 1076S-1081S.

33. Tran AT, Ramalinga M, Kedir H, Clarke R, Kumar D (2015) Autophagy inhibitor 3-methyladenine potentiates apoptosis induced by dietary tocotrienols in breast cancer cells. Eur J Nutr 54: 265.

34. Behery FA, Ak MR, Ananthula S, Parajuli P, Sylvester PW (2013) Optimization of tocotrienols as antiproliferative and antimigratory leads. Eur J Med Chem 59: 329-341.

35. Sylvester PW, AkI MR, Malaviya A, Parajuli P, Ananthula S, et al. (2014) Potential role of tocotrienols in the treatment and prevention of breast cancer. Biofactors 40: 49-58.

36. McIntyre BS, Briski KP, Tirmenstein MA, Fariss MW, Gapor A, et al. (2000) Antiproliferative and apoptotic effects of tocopherols and tocotrienols on preneoplastic and neoplastic mouse mammary epithelial cells. Proc Socr Expl Biol Med 224: 292-301.

37. Shah SJ, Sylvester PW (2005) Tocotrienol-induced cytotoxicity is unrelated to mitochondrial stress apoptotic signaling in neoplastic mammary epithelial cells. Biochem Cell Biol 83: 86-95.

38. Nesaretnam K (2004) Tocotrienolrich fraction from palm oil and gene expression in human breast cancer cells. Ann NY Acad Sci 1031: 143-157.

39. Pierpaoli E, Viola V, Barucca A, Orlando F, Galli F, et al. (2013) Effect of annatto-tocotrienols supplementation on the development of mammary tumors in HER-2/neu transgenic mice. Carcinogenesis 34: 1352-1360.

40. Kline K, Yu W, Sanders BG (2004) Vitamin E and breast cancer. J Nutr 134: 3458S-3462S.

41. Ananthula S, Parajuli P, Behery FA, Alayoubi AY, El Sayed KA, et al. (2014) Oxazine derivatives of $\gamma$-and $\delta$-tocotrienol display enhanced anticancer activity in vivo. Anticancer Res 34: 2715-2726.

42. Lavaud A, Richomme P, Litaudon $M$, Andriantsitohaina R, Guilet D (2013) Antiangiogenic tocotrienol derivatives from Garcinia amplexicaulis. J Nat Prod 76: 2246-2252.

43. Kamal-Eldin A, Lars-Ake A (1996) The chemistry and antioxidant properties of tocopherols and tocotrienols. Lipids 31: 671-701.

44. Karim R, Somani S, Robaian MA, Mullin M, Amor R, et al. (2017) Tumor regression after intravenous administration of targeted vesicles entrapping the vitamin E $\alpha$-tocotrienol. J Control Release 246: 79-87. 